\title{
DC Performance Variations of SOI FinFETs with Different Silicide Thickness
}

\author{
Jun-Sik Yoon \\ POSTECH Information Research Laboratories, Pohang 37673, Republic of Korea \\ Correspondence should be addressed to Jun-Sik Yoon; junsikyoon@postech.ac.kr
}

Received 30 January 2018; Revised 4 April 2018; Accepted 12 April 2018; Published 17 May 2018

Academic Editor: Da-Ren Hang

Copyright (C) 2018 Jun-Sik Yoon. This is an open access article distributed under the Creative Commons Attribution License, which permits unrestricted use, distribution, and reproduction in any medium, provided the original work is properly cited.

DC performance and the variability of $n$-type silicon-on-insulator dopant-segregated FinFETs with different silicide thickness $\left(T_{\text {sili }}\right)$ are analyzed. DC parameters including threshold voltage, low-field-mobility-related coefficient, and parasitic resistance are extracted from $Y$-function method for the comparison of DC performance and variability, and the correlation analysis. All the devices show similar subthreshold characteristics, but the devices with thicker $T_{\text {sili }}$ have greater threshold voltages. The devices with thicker $T_{\text {sili }}$ suffer from the DC performance degradation and its greater variations because the Schottky barrier height at the $\mathrm{NiSi} / \mathrm{Si}$ interface increases and fluctuates greatly. This effect is validated by greater threshold voltages, larger parasitic resistances, and high correlations among all the DC parameters for the thicker $T_{\text {sili }}$. The devices with thicker $T_{\text {sili }}$ also have higher low-frequency noise because of larger parasitic resistances and their correlated mobility degradations. Therefore, the device with relatively thin $T_{\text {sili }}$ is expected to have better DC performance and variability concerns.

\section{Introduction}

Silicon-on-insulator (SOI) MOSFETs maintain short channel immunity successfully due to the absence of substrate leakage current [1]. SOI-based devices having fin-shaped [2], ultra-thin-body [3], or gate-all-around [4] channel regions attain great scalability without short channel degradation. Meanwhile, dopant-segregated SOI MOSFETs have been considered as one of the promising candidates due to their several advantages over the planar bulk MOSFETs: low Schottky barrier height (SBH) at the silicide/semiconductor interface, possibility of low-temperature process, and nearabrupt junction formation [5-9]. Not only MOSFETs but also tunneling FETs also utilize abrupt doping profile to enhance the band-to-band tunneling transport at the source/channel junction $[10,11]$.

Two-step annealing process during silicidation was suggested to decrease the lateral excursion of silicide into the channel region [12]. The influence of NiPt thickness prior to silicidation on the DC performance of SOI MOSFETs has been studied [13]. Increasing the NiPt thickness increased the contact resistance due to the decreased interfacial area between silicide and semiconductor but decreased the variations of sheet resistance due to its full silicidation. In this regard, it is necessary to analyze both DC performance and its variability in the perspective of the silicidation for the nanoscale dopant-segregated SOI MOSFETs.

Thus, DC performance and variations of SOI FinFETs with different silicide thickness $\left(T_{\text {sili }}\right)$ were investigated. Then, the variability sources inducing the drain current $\left(I_{\mathrm{ds}}\right)$ variations were studied using the correlation analysis. Lowfrequency noise was also measured for the detailed analysis of the devices with different $T_{\text {sili }}$.

\section{Materials and Methods}

(100) undoped SOI with 140-nm-thick buried oxide (BOX) and 20 -nm-thick top Si region was prepared. BOX overetching process was performed to define omega-shaped fin structure as shown in Figure 1(b) of [13]. After the formation of gate stack $\left(\mathrm{HfO}_{2}\right.$, TiN, amorphous-Si), Arsenic dopants were implanted at extension regions to reduce the underlap resistance. After defining nitride spacer regions with the spacer length $\left(L_{\mathrm{sp}}\right)$ of $20 \mathrm{~nm}$, low-energy implantation and annealing at $1070^{\circ} \mathrm{C}$ and $1.5 \mathrm{~s}$ were done for the source/drain (S/D) regions. Different from [13] where the NiPt with 


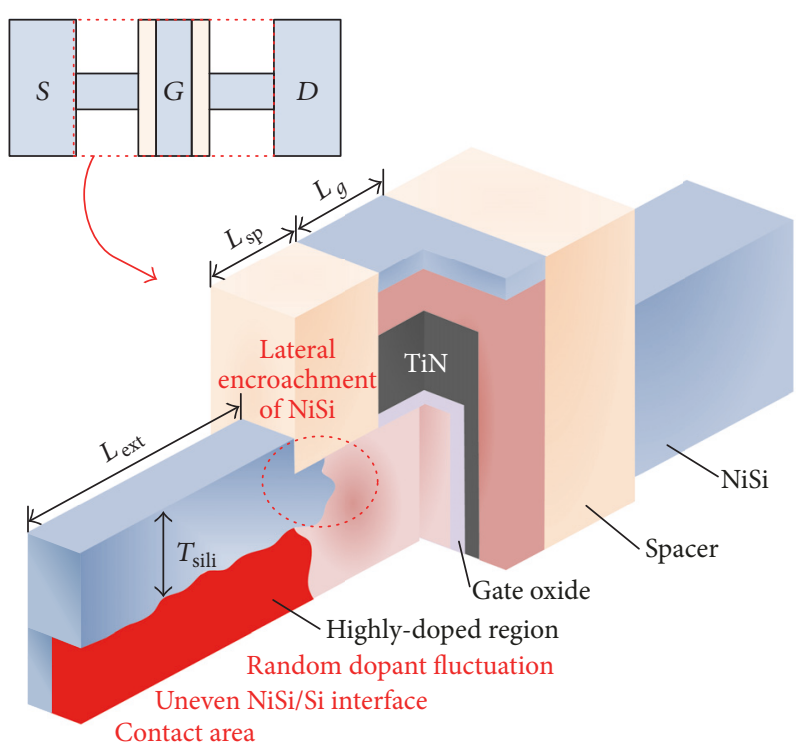

FIGURE 1: 3D schematic diagram of the SOI FinFETs. Geometrical parameters such as gate length $\left(L_{g}\right)$, spacer length $\left(L_{\text {sp }}\right)$, extension length $\left(L_{\text {ext }}\right)$, and silicide thickness $\left(T_{\text {sili }}\right)$ are also specified. Top left figure describes the real device structure, and red-colored phrases indicate the possible variability sources.

different thickness of 5 or $10 \mathrm{~nm}$ was deposited, the same 10nm-thick NiPt (4\% Pt) was deposited and annealed under two-step rapid thermal process (RTP) conditions to remove the unreacted NiPt in the middle. Instead, different RTP temperature and time conditions were used to form the $\mathrm{NiSi}$ with different $T_{\text {sili }}$ of 8 and $10 \mathrm{~nm}$. Otherwise, all the measured devices have the equivalent number of fins $\left(N_{\text {fin }}\right)$ of 2 , fin width $\left(W_{\text {fin }}\right)$ of $40 \mathrm{~nm}$, fin height $\left(H_{\text {fin }}\right)$ of $20 \mathrm{~nm}$, extension length $\left(L_{\text {ext }}\right)$ of $80 \mathrm{~nm}$, and gate length $\left(L_{g}\right)$ of $40 \mathrm{~nm}$. The detailed process flow and device geometry are shown in [13].

All the devices have the active regions with equivalent size and structure, so the differences of DC performances and the variations are induced mostly by different $T_{\text {sili }}$. Figure 1 shows the possible variability sources of the S/D regions. Uneven $\mathrm{NiSi} / \mathrm{Si}$ interface [14] and random dopant fluctuation (RDF) $[15,16]$ can also fluctuate the contact resistivity and thus induce the DC performance variations. Different NiSi/Si contact area by different $T_{\text {sili }}$ would also affect the DC performance and variations because typical transfer lengths, defined as the distances that carriers below the contact travel before entering into the contact, of SOI devices are in the order of $100 \mathrm{~nm}[17,18]$, which is longer than $L_{\text {ext }}$. Different RTP conditions involved with different $T_{\text {sili }}$ can vary the device performance by statistical piping effect [19] or lateral encroachment of NiSi into the S/D extension regions [20]. To understand DC performance and its variations for different $T_{\text {sili }}$, their transfer characteristics were measured using Keithley 4200 semiconductor characterization system, whereas low-frequency noise was measured using HP 89410A vector signal analyzer.

\section{Results and Discussion}

3.1. DC Performance and Variations at Different Silicide Thickness. $I_{\mathrm{ds}}$ and transconductance $\left(g_{m}\right)$ of the 50 measured devices each with different $T_{\text {sili }}$ of 8 and $10 \mathrm{~nm}$ are shown in Figure 2. Each wafer has a different $T_{\text {sili }}$, and the measured devices with each $T_{\text {sili }}$ are at the same position of each wafer to minimize the die-to-die variations between two different $T_{\text {sili }}$. Gate voltage $\left(V_{\mathrm{gs}}\right)$ is swept from 0.0 to $1.3 \mathrm{~V}$ in steps of $0.02 \mathrm{~V}$, and drain voltages $\left(V_{\mathrm{ds}}\right)$ are 0.05 and $1.0 \mathrm{~V}$. Red lines indicate the averages of $I_{\mathrm{ds}}$ and $g_{m}$ for each $T_{\text {sili }}$. In both linear and saturation regimes, the devices with $T_{\text {sili }}$ of $8 \mathrm{~nm}$ have greater DC performance by showing higher on-state currents $\left(I_{\text {on }}\right)$, while the subthreshold characteristics for $T_{\text {sili }}$ of 8 and $10 \mathrm{~nm}$ are similar. Figure 2(c) shows that all the devices with $T_{\text {sili }}$ of 8 and $10 \mathrm{~nm}$ do not have ambipolar effects at high $V_{\mathrm{ds}}$ of $1.0 \mathrm{~V}$ near the off-state, validating the absence of Schottky contact [13].

$R_{\text {on }}\left(=V_{\mathrm{ds}} / I_{\mathrm{on}}\right)$ values of the 20 measured devices each with different $W_{\text {fin }}$ and $T_{\text {sili }}$ are shown in Figure S1. $I_{\text {on }}$ are extracted at the gate overdrive voltage $\left(V_{\mathrm{gs}}-V_{\text {th_CCM }}\right)$ of $1.0 \mathrm{~V}$, where $V_{\text {th_CCM }}$ is the threshold voltage $\left(V_{\text {th }}\right)$ extracted from constant current method (CCM) at $I_{\text {th }}=W_{\text {eff }} / L_{g} \cdot 10^{-7} \mathrm{~A}$ $\left(W_{\text {eff }}=N_{\text {fin }} \cdot\left(2 H_{\text {fin }}+W_{\text {fin }}\right)\right)$. The devices with $T_{\text {sili }}$ of $8 \mathrm{~nm}$ have smaller $R_{\text {on }}$ for all $W_{\text {fin }}$. But the difference of $R_{\text {on }}$ between two different $T_{\text {sili }}$ is smaller for greater $W_{\text {fin }}$ because the ratio of the NiSi/Si contact area between two different $T_{\text {sili }}$ decreases. Additionally, raised S/D structure would be beneficial to improve the DC performance by increasing the NiSi/Si contact area. But for raised S/D structure, likewise, thicker $T_{\text {sili }}$ also decreases the contact area, increases the contact resistance, and thus degrades the DC performance [21].

Several parameters from the transfer characteristics are extracted to analyze the DC performance variations: $V_{\mathrm{th}}$, lowfield-mobility-related coefficient $\left(X_{0}\right)$, and parasitic resistance $\left(R_{\mathrm{sd}}\right) . V_{\text {th }}$ values are extracted using CCM or $Y$-function method $[16,22] . V_{\text {th_CCM }}$ is measured at $I_{\text {th }}=W_{\text {eff }} / L_{g} \cdot 10^{-8} \mathrm{~A}$, whereas $V_{\text {th }}$ from $Y$-function method $\left(V_{\text {th }-y}\right)$ is extracted from the $x$-axis intercept of the linearly extrapolated curve as shown in Figure 3.

The simple and general expression of $I_{\mathrm{ds}}$ at low $V_{\mathrm{ds}}$ in the strong inversion regime is given by

$$
I_{\mathrm{ds}}=X_{0} \cdot\left(V_{\mathrm{gs}}-V_{\text {th_y }}\right) \cdot\left(V_{\mathrm{ds}}-I_{\mathrm{ds}} R_{\mathrm{sd}}\right),
$$

where $X_{0}$ is defined as $\mu_{\text {eff }} \cdot C_{\text {ox }} \cdot W_{\text {eff }} / L_{g}\left(\mu_{\text {eff }}\right.$ is effective mobility and $C_{\text {ox }}$ is oxide capacitance). $Y$-function is simply expressed as

$$
Y \equiv \frac{I_{\mathrm{ds}}}{\sqrt{g_{m}}}=\sqrt{X_{0} \cdot\left(V_{\mathrm{ds}}-I_{\mathrm{ds}} R_{\mathrm{sd}}\right)} \cdot\left(V_{\mathrm{gs}}-V_{\mathrm{th}-y}\right) .
$$

According to (2), $Y$-function is linear in the strong inversion regime if $X_{0}$ or $\mu_{\text {eff }}$ does not depend on $V_{\mathrm{gs}}$. In other words, the $Y$-function does not satisfy the linearity condition if the devices suffer from surface roughness scattering greatly [22]. Another assumption is that $I_{\mathrm{ds}} \cdot R_{\mathrm{sd}}$ is almost invariant to $V_{\mathrm{gs}}$ and smaller than $V_{\mathrm{ds}}$ in the strong inversion regime, which is satisfied in this study. Almost all the measured devices also meet the linearity condition at $V_{\mathrm{ds}}$ of $0.05 \mathrm{~V}$ (Figure 3) 


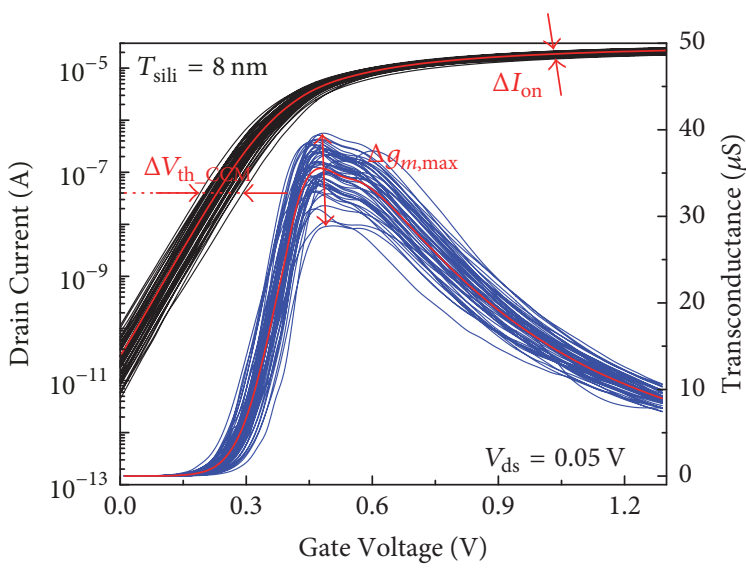

(a)

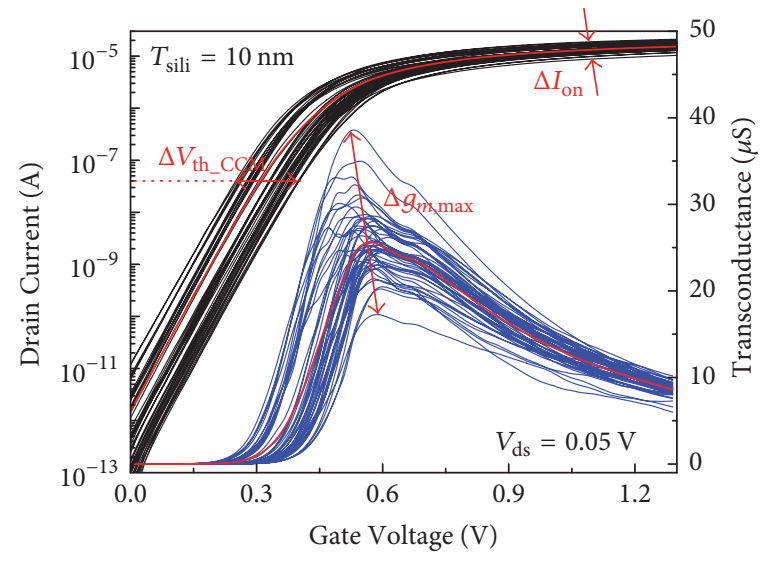

(b)

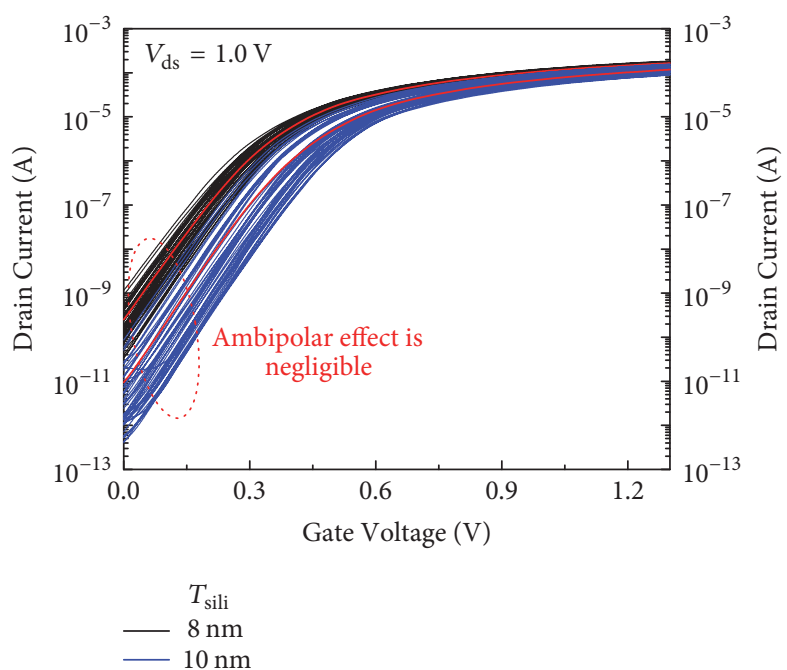

(c)

FIGURE 2: DC performance and variations of the SOI FinFETs with the $T_{\text {sili }}$ of (a) 8 and (b) $10 \mathrm{~nm}$ at drain voltage $\left(V_{\mathrm{ds}}\right)$ of $0.05 \mathrm{~V}$ and (c) $1.0 \mathrm{~V}$. The number of measured devices is 50 for each $T_{\text {sili }}$.

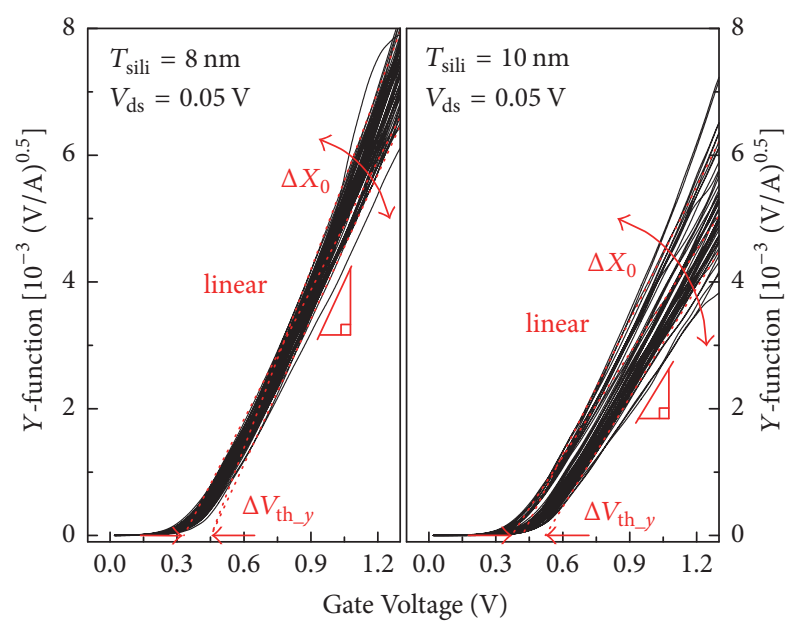

FIGURE 3: $Y$-function variations of the SOI FinFETs with $T_{\text {sili }}$ of 8 and $10 \mathrm{~nm}$. Almost all the $Y$-functions satisfy the linearity condition in the strong inversion regime. because all the devices have omega-shaped structure with ultra-thin fin channel, which induces volume inversion and thus attenuates the surface roughness scattering.

Figure 4 shows $V_{\text {th_ } y}, X_{0}$, and $R_{\text {sd }}$ of the measured devices at $V_{\mathrm{ds}}$ of $0.01,0.02,0.03,0.04$, and $0.05 \mathrm{~V}$ extracted from $Y$ function method. Average $X_{0}$ and $R_{\mathrm{sd}}$ are independent of $V_{\mathrm{ds}}$, whereas $V_{\text {th } y}$ increases slightly as $V_{\mathrm{ds}}$ increases. $V_{\text {th_ } y}$ includes the band-bending by gate voltage as well as the body-effect expressed by $m / 2 \cdot V_{\mathrm{ds}}$, where $m$ is the body-effect coefficient ( $m$ is simply approximated as 1 for fully depleted devices), thus showing a slight increase of $V_{\text {th } y}$ with the slope of $V_{\mathrm{ds}} / 2$ as $V_{\mathrm{ds}}$ increases [23]. The devices with $T_{\text {sili }}$ of $8 \mathrm{~nm}$ show greater $X_{0}$ and smaller $R_{\text {sd }}$ due to greater $\mathrm{NiSi} / \mathrm{Si}$ contact area.

The devices with $T_{\text {sili }}$ of $10 \mathrm{~nm}$ have greater variations of $V_{\text {th_ } y}, X_{0}$, and $R_{\text {sd }}$ (Figure 4). Standard deviations $(\sigma)$ of $X_{0}$ and $R_{\text {sd }}$ for $T_{\text {sili }}$ of $10 \mathrm{~nm}$ increase by 62.4 and $48.5 \%$, respectively, with respect to those for $T_{\text {sili }}$ of $8 \mathrm{~nm}$. Not only $V_{\text {th_y }}$ but also $V_{\text {th_CCM }}$ variations are severer for $T_{\text {sili }}$ of $10 \mathrm{~nm}$ 




FIGURE 4: Average and standard deviations of dc parameters for the SOI FinFETs with $T_{\text {sili }}$ of $8 \mathrm{~nm}$ (black) and $10 \mathrm{~nm}$ (red) at different $V_{\mathrm{ds}}$ : $V_{\text {th_y }}, X_{0}$, and $R_{\text {sd. }}$.

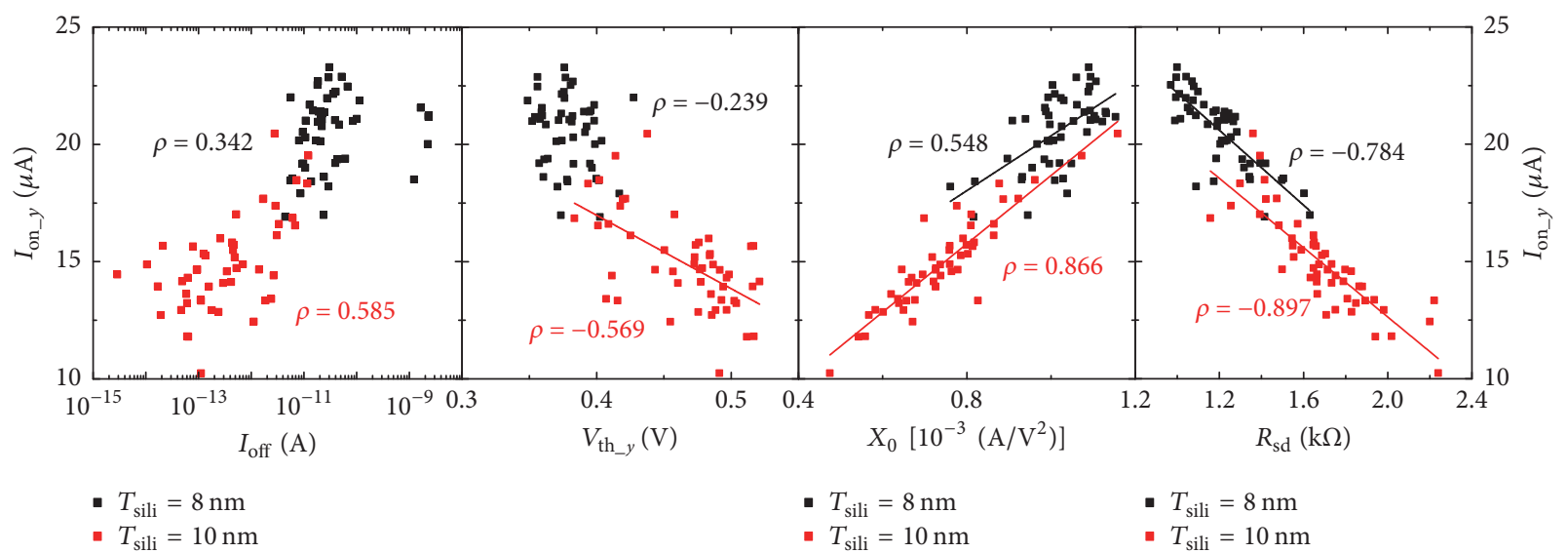

FIGURE 5: Scatter plots of $I_{\text {on_ } y}$ at $\left(V_{\text {gs }}-V_{\text {th_ } y}\right)$ of $0.8 \mathrm{~V}$ with respect to the DC parameters $\left(I_{\text {off }}, V_{\text {th_- } y}, X_{0}\right.$, and $\left.R_{\text {sd }}\right)$ for the SOI FinFETs at $V_{\text {ds }}$ of $0.05 \mathrm{~V}$. All the linear regressions indicate the sensitivity of $I_{\text {on- } y}$ with respect to the DC parameters.

$(\sigma=45 \mathrm{mV})$ than for $T_{\text {sili }}$ of $8 \mathrm{~nm}(\sigma=22 \mathrm{mV})$ at all different $V_{\mathrm{ds}}$.

3.2. DC Performance Variability Analysis. To investigate why the devices with $T_{\text {sili }}$ of $10 \mathrm{~nm}$ suffer from smaller DC performance and greater variations, correlation analysis of $I_{\text {on }}$ with off-state currents $\left(I_{\text {off }}\right), V_{\text {th }-y}, X_{0}$, and $R_{\text {sd }}$ is done in Figure 5. Spearman's correlation is used to calculate the correlation coefficient $(\rho)[15] . I_{\text {off }}$ values are $I_{\mathrm{ds}}$ at $V_{\text {gs }}$ of $0.0 \mathrm{~V}$, whereas all the $I_{\text {on }}$ values are extracted at the gate overdrive voltage $\left(V_{\mathrm{gs}}-V_{\mathrm{th}-y}\right)$ of $0.8 \mathrm{~V}\left(I_{\mathrm{on}_{-} y}\right)$ to neglect the $V_{\mathrm{th}-y}$ effect [24]. Since all the devices have similar SS and no gate-induced drain leakages, $I_{\text {off }}$ is mostly determined by $V_{\text {th_y }}(\rho=-0.781$ and -0.907 for $T_{\text {sili }}$ of 8 and $10 \mathrm{~nm}$, resp.). Due to these perspectives, therefore, a slight correlation between $I_{\text {on_ } y}$ and $I_{\text {off }}$ along with $V_{\text {th_y }}$ is expected.
Nonetheless, there are correlations between $I_{\text {off }}, V_{\text {th_ } y}$, and $I_{\text {on_y } y}$ for $T_{\text {sili }}$ of $10 \mathrm{~nm}$ (left of Figure 5). In addition, $V_{\text {th_ } y}$ for $T_{\text {sili }}$ of $10 \mathrm{~nm}$ is correlated with $X_{0}(\rho=-0.530)$ and $R_{\text {sd }}(\rho=0.491)$, whereas $V_{\text {th_y }}$ for $T_{\text {sili }}$ of $8 \mathrm{~nm}$ is independent of $X_{0}(\rho=-0.077)$ and $R_{\mathrm{sd}}(\rho=0.200)$ at all different $V_{\mathrm{ds}}$. $X_{0}$ is also correlated with $R_{\text {sd }}$ for $T_{\text {sili }}$ of $10 \mathrm{~nm}(\rho=-0.581)$, whereas the correlation is small for $T_{\text {sili }}$ of $8 \mathrm{~nm}(\rho=-0.162)$.

These high correlations among all the DC parameters ( $\left.I_{\text {off }}, V_{\text {th_ } y}, X_{0}, R_{\text {sd }}\right)$ and $I_{\text {on_ }_{-} y}$ for $T_{\text {sili }}$ of $10 \mathrm{~nm}$ are related to the high SBH at the NiSi/Si interface. Higher SBH for thicker $T_{\text {sili }}$ is expected due to greater lateral encroachment of $\mathrm{NiSi}$ into the S/D extension regions $[19,25]$. Greater $V_{\text {th_CCM }}$ (or $\left.V_{\text {th_y }}\right)$ and larger $R_{\text {sd }}$ for $T_{\text {sili }}$ of $10 \mathrm{~nm}$ are the indicatives of higher SBH according to equation (2) in [26] and higher contact resistivity [27], respectively. Higher SBH for thicker $T_{\text {sili }}$ requires much band-bending for the carrier injection from source (related with $I_{\text {off }}$ and $V_{\text {th_y }}$ ) and impedes carrier 


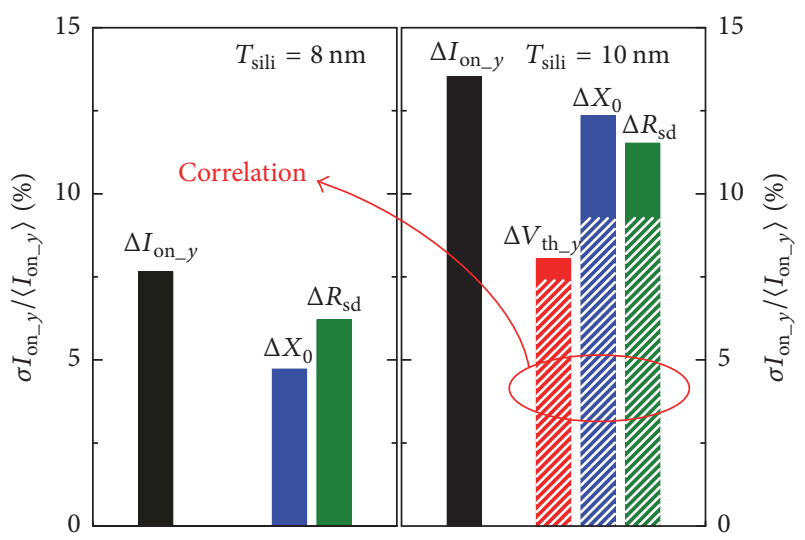

FIGURE 6: $I_{\text {on_ } y}$ variations and variations of the dc parameters $\left(V_{\text {th- } y}\right.$, $X_{0}$, and $\left.R_{\text {sd }}\right)$ contributing to the $I_{\text {on_y }}$ variations for $T_{\text {sili }}$ of 8 and $10 \mathrm{~nm}$.

flow under operation (related with $X_{0}, R_{\text {sd }}$, and thus $I_{\text {on-y }}$ ) [28]. For the low-SBH devices, the $\mathrm{SBH}$ variations induce the on-state performance variations, not the $V_{\text {th }}$ variations [26]. Therefore, the $V_{\text {th }}$ variations for $T_{\text {sili }}$ of $8 \mathrm{~nm}$ are dominantly induced by other variability sources (gate work function (WF) variation [24], RDF [15], and interface traps [29]) except the SBH. And that is why $V_{\text {th- } y}$ for $T_{\text {sili }}$ of $8 \mathrm{~nm}$ is not correlated with $X_{0}, R_{\text {sd }}$, and $I_{\text {on_ } y}$.

Greater variations of all the DC parameters for $T_{\text {sili }}$ of 10 $\mathrm{nm}$ can also explain the increased SBH and its variations. The $R_{\text {sd }}$ variations for SOI FinFETs are dominantly affected by $\mathrm{NiSi} / \mathrm{Si}$ contact resistance $[20,27]$. The $\mathrm{NiSi} / \mathrm{Si}$ interface consists of NiSi crystal grains having different WF and surface roughness [14]. The extension regions suffer from RDF [15] along with the WF variations, having different $\mathrm{SBH}$ at each of NiSi crystal grains and also for each of the devices. And this induces the SBH variations greatly for $T_{\text {sili }}$ of $10 \mathrm{~nm}$ due to smaller contact area.

Figure 6 shows the relative contributions to the $I_{\text {on }-y}$ variations with respect to the DC parameters each. When the DC parameters are correlated with each other, the contributions to the variations of $I_{\text {on_ } y}$ for the correlated portion are calculated using the correlation coefficient, sensitivity (the slope of scatter plots in Figure 5), and standard deviations [24]. All the correlated portions are presented as the shaded area. All the three DC parameters are correlated with each other and the $X_{0}$ variations affect the $I_{\text {on_ } y}$ variations greatly for $T_{\text {sili }}$ of $10 \mathrm{~nm}$, whereas they are independent and the $R_{\mathrm{sd}}$ variations affect the $I_{\text {on- } y}$ variations greatly for $T_{\text {sili }}$ of $8 \mathrm{~nm}$.

3.3. Low-Frequency Noise Analysis. Low-frequency noise was measured at $V_{\mathrm{ds}}$ of $0.05 \mathrm{~V}$ and at the overdrive voltage $\left(V_{\mathrm{ov}}=\right.$ $V_{\mathrm{gs}}-V_{\text {th_CCM }}$ ) of $0.3 \mathrm{~V}$ (Figure 7). Frequency range was from 1 to $1000 \mathrm{~Hz}$, and the 10 devices each with $T_{\text {sili }}$ of 8 and $10 \mathrm{~nm}$, closest to the average $I_{\mathrm{ds}}$, were measured. All the results follow the $1 / f$ trend except at the frequency near $1 \mathrm{~Hz}$ where Lorentzian-type noise plateau is observed due to the smallarea devices. The devices with $T_{\text {sili }}$ of $10 \mathrm{~nm}$ have greater average $S_{\text {Ids }}$ for all the frequency range.
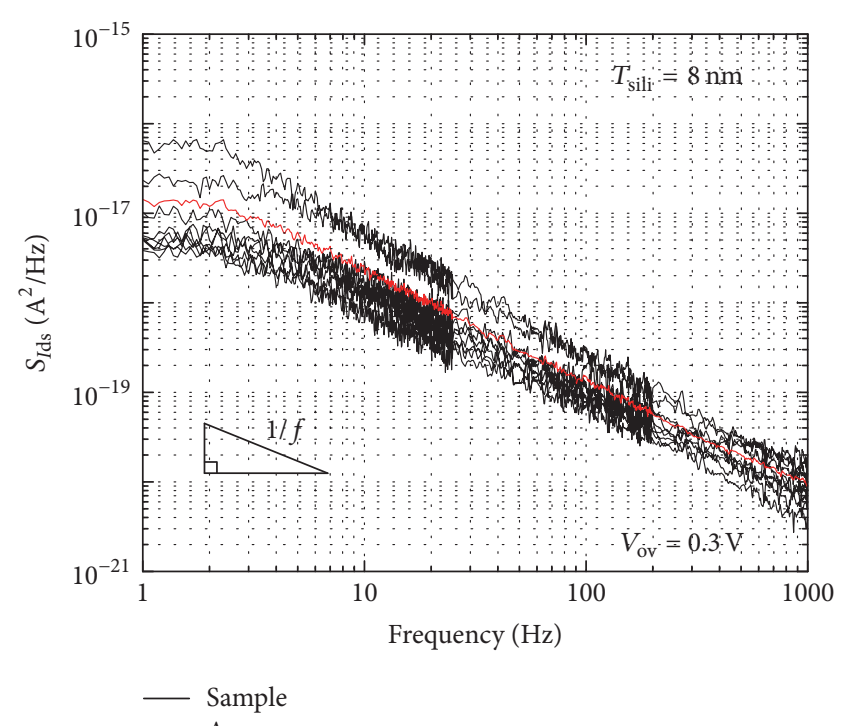

- Average

(a)

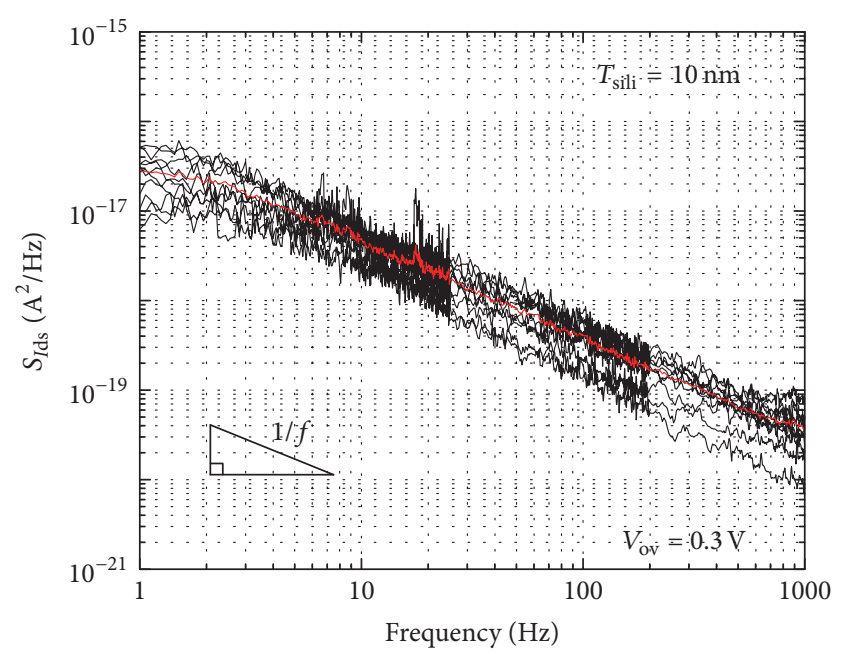

- Sample
- Average

(b)

FIGURE 7: Drain current noise spectral density $\left(S_{\text {Ids }}\right)$ measured at $V_{\mathrm{ds}}$ of $0.05 \mathrm{~V}$ and the overdrive voltage $\left(V_{\mathrm{ov}}=V_{\mathrm{gs}}-V_{\text {th_CCM }}\right)$ of $0.3 \mathrm{~V}$ for $T_{\text {sili }}$ of (a) 8 and (b) $10 \mathrm{~nm}$. The number of measured devices, close to the average $I_{\mathrm{ds}}$, is 10 each.

Figure 8 shows $S_{I \mathrm{ds}}$ normalized by $I_{\mathrm{ds}}{ }^{2}$ of the devices with different $T_{\text {sili }}$ at $V_{\text {ov }}$ from 0.1 to $0.6 \mathrm{~V}$ in steps of $0.1 \mathrm{~V}$ measured at $10 \mathrm{~Hz}$. In case of $V_{\mathrm{ov}}$ from 0.3 to $0.6 \mathrm{~V}$, the normalized $S_{I \mathrm{Ids}}$ values are almost independent of $V_{\mathrm{ov}}$, where the noise induced by $R_{\text {sd }}\left(S_{R s d}\right)$ is dominant to the device [30]. The noise within the channel $\left(S_{R \mathrm{ch}}\right)$ is from the $\mathrm{Si} / \mathrm{SiO}_{2}$ interface and the channel itself, whereas $S_{R s d}$ is from the S/D contact at $\mathrm{NiSi} / \mathrm{Si}$ interface. But the quality of $\mathrm{Si} / \mathrm{SiO}_{2}$ interface is almost similar for all the devices because the only difference is RTP, performed under low temperature around $300 \sim 450^{\circ} \mathrm{C}[13,19$, $20,31,32]$ enough not to induce the $\mathrm{Si} / \mathrm{SiO}_{2}$ interface damage. In spite of that, the devices with $T_{\text {sili }}$ of $10 \mathrm{~nm}$ have greater 


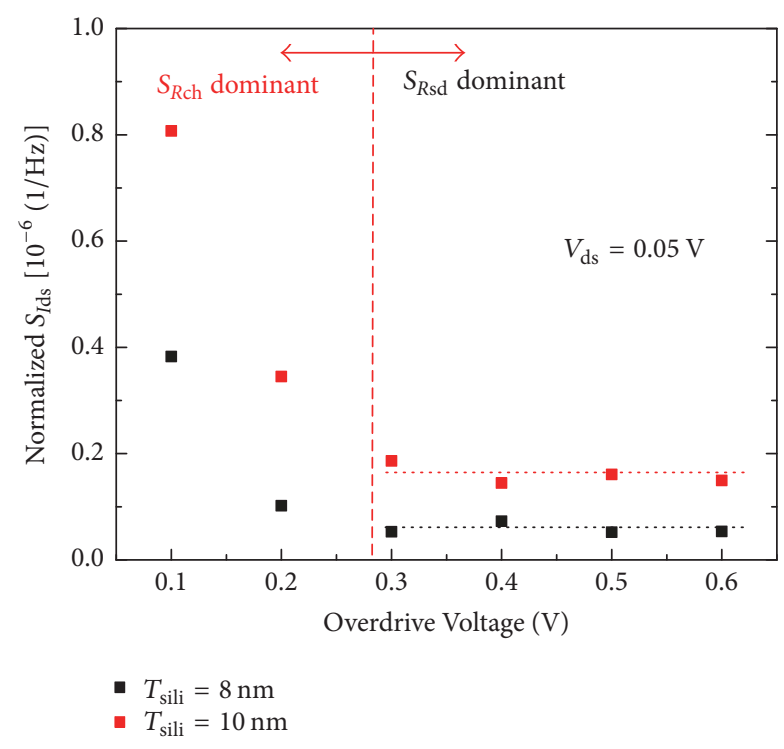

FIgURE 8: Normalized $S_{I \mathrm{ds}}$ at $10 \mathrm{~Hz}$ with respect to $I_{\mathrm{ds}}$ at different $V_{\text {ov}}$.

$S_{R \text { ch }}$ because high SBH close to the lightly doped extension region decreases $X_{0}$ (related to $\mu_{\text {eff }}$ ) which is correlated with $R_{\text {sd }}$. Greater $S_{R \text { ch }}$ for $T_{\text {sili }}$ of $10 \mathrm{~nm}$ is also explained by the lateral encroachment of NiSi into the S/D extension regions. More lateral encroachment of $\mathrm{NiSi}$ for thicker $T_{\text {sili }}$ induces higher SBH, which impedes the carrier flow and decreases the channel length [33]. These physical phenomena increase $S_{R \mathrm{ch}}$ according to equation (3) of [30]; thus the greater $S_{R \mathrm{ch}}$ for $T_{\text {sili }}$ of $10 \mathrm{~nm}$ is obtained (Figure 8). As a result, the devices with $T_{\text {sili }}$ of $10 \mathrm{~nm}$ have greater normalized $S_{\text {Ids }}$ for all $V_{\text {ov }}$.

\section{Conclusions}

DC performance and variability of the dopant-segregated SOI FinFETs with different $T_{\text {sili }}$ are analyzed in terms of the DC parameters extracted from $Y$-function method and Spearman correlation, respectively. Thicker $T_{\text {sili }}$ degrades DC performance by decreasing $I_{\text {on }}$ and $g_{m \text {, max }}$ and fluctuates $V_{\text {th }}$, $X_{0}, R_{\text {sd }}$, and $I_{\text {on }}$ greatly because the SBH increases greatly and varies along with WF variation and $R D F$ at the $S / D$ region. In addition, the devices with $T_{\text {sili }}$ of $10 \mathrm{~nm}$ suffer from large lowfrequency noise due to high $\mathrm{SBH}$, which is caused by greater lateral encroachment of $\mathrm{NiSi}$ into the $\mathrm{S} / \mathrm{D}$ extension regions and related to greater variations and correlations of $V_{\text {th_y }}, X_{0}$, $R_{\text {sd }}$, and $I_{\text {on }-y}$. Therefore, the device with relatively thin $T_{\text {sili }}$ is promising to improve DC performance and minimize the variation.

This variability study would be helpful to design nanoscale devices having a few dopants and small contact area because the $\mathrm{SBH}$ values and variations of the devices depend on $T_{\text {sili }}$ greatly.

\section{Data Availability}

All the data analyzed in this study are included in this published article.

\section{Conflicts of Interest}

The author declares that there are no conflicts of interest regarding the publication of this paper.

\section{Acknowledgments}

The author would like to thank SEMATECH for device fabrication. This work was supported in part by the Ministry of Science and ICT, South Korea, through the ICT Consilience Creative Program under Grant IITP-2017-R034616-1007 supervised by the Institute for Information and Communications Technology Promotion.

\section{Supplementary Materials}

Supplementary materials contain one figure (Figure S1). Figure S1: on-state resistance $\left(R_{\mathrm{on}}\right)$ as a function of fin width $\left(W_{\text {fin }}\right)$ for different $T_{\text {sili }}$ of 8 and $10 \mathrm{~nm}$. The number of fins $\left(N_{\text {fin }}\right)$ for each device is 20 . As $W_{\text {fin }}$ increases from 40 to $80 \mathrm{~nm}$, the difference of $R_{\text {on }}$ between two different $T_{\text {sili }}$ decreases from 36 to 23\%. (Supplementary Materials)

\section{References}

[1] T. Chiarella, L. Witters, A. Mercha et al., "Benchmarking SOI and bulk FinFET alternatives for PLANAR CMOS scaling succession," Solid-State Electronics, vol. 54, no. 9, pp. 855-860, 2010.

[2] C-H. Lin, B. Greene, S. Narasimha et al., "High performance $14 \mathrm{~nm}$ SOI FinFET CMOS technology with $0.0174 \mu \mathrm{m} 2$ embedded DRAM and 15 levels of Cu metallization," in Proccedings of IEEE International Electron Devices Meeting (IEDM), pp. 74-76, 2014.

[3] Q. Liu, A. Yagishita, and N. Loubet, "UTBB) fully depleted (FD) device integration for 22?nm node and beyond," VLSI Tech. Dig, pp. 61-62, 2010.

[4] S. Barraud, R. Coquand, V. Maffini-Alvaro, and et al, "Scaling of $\Omega$-gate SOI nanowire $\mathrm{n}$ - and $\mathrm{p}$-FET down to $10 \mathrm{~nm}$ gate length: size- and orientation-dependent strain effects," in Proceedings of the VLSI Technology, Symposium, pp. 230-231, 2013.

[5] V. Gudmundsson, P.-E. Hellstrom, J. Luo, J. Lu, S.-L. Zhang, and M. Östling, "Fully depleted UTB and trigate N-channel MOSFETs featuring low-temperature PtSi Schottky-barrier contacts with dopant segregation," IEEE Electron Device Letters, vol. 30, no. 5, pp. 541-543, 2009.

[6] M. J. Martin, E. Pascual, and R. Rengel, "RF dynamic and noise performance of Metallic Source/Drain SOI n-MOSFETs," SolidState Electronics, vol. 73, pp. 64-73, 2012.

[7] M. H. Khater, Z. Zhang, J. Cai et al., "High-k/metal-gate fully depleted SOI CMOS with single-silicide Schottky source/drain with sub-30-nm gate length," IEEE Electron Device Letters, vol. 31, no. 4, pp. 275-277, 2010.

[8] J. Knoch, M. Zhang, S. Feste, and S. Mantl, "Dopant segregation in SOI Schottky-barrier MOSFETs," Microelectronic Engineering, vol. 84, no. 11, pp. 2563-2571, 2007.

[9] Z. Zhang, F. Pagette, C. D'Emic et al., "Sharp reduction of contact resistivities by effective schottky barrier lowering with silicides as diffusion sources," IEEE Electron Device Letters, vol. 31, no. 7, pp. 731-733, 2010. 
[10] K. Jeon, W.-Y. Loh, and P. Patel, "Si tunnel transistors with a novel silicided source and $46 ? \mathrm{mV} / \mathrm{dec}$ swing," in Proceedings of the VLSI Technology, Symposium, pp. 121-122, 2010.

[11] L. Hutin, C. Le Royer, R. P. Oeflein et al., "Detecting Unintended Schottky Junctions and Their Impact on Tunnel FET Characteristics," IEEE Transactions on Electron Devices, vol. 63, no. 6, pp. 2577-2582, 2016.

[12] J. Luo, D. Wu, Z. Qiu et al., "On different process schemes for MOSFETs with a controllable nisi-based metallic source/drain," IEEE Transactions on Electron Devices, vol. 58, no. 7, pp. 18981906, 2011.

[13] K. Akarvardar, M. Rodgers, V. Kaushik et al., "Impact of NiPt thickness scaling on contact resistance from thin-body FD SOI to trigate FETs," IEEE Electron Device Letters, vol. 33, no. 5, pp. 631-633, 2012.

[14] Z. Zhang, J. Lu, Z. Qiu, P.-E. Hellström, M. Östling, and S. L. Zhang, "Performance fluctuation of FinFETs with Schottky barrier source/drain," IEEE Electron Device Letters, vol. 29, no. 5, pp. 506-508, 2008.

[15] J. Yoon, T. Rim, J. Kim, K. Kim, C. Baek, and Y. Jeong, "Statistical variability study of random dopant fluctuation on gate-allaround inversion-mode silicon nanowire field-effect transistors," Applied Physics Letters, vol. 106, no. 10, p. 103507, 2015.

[16] J.-S. Yoon, K. Kim, T. Rim, and C.-K. Baek, "Variability study of Si nanowire FETs with different junction gradients," AIP Advances, vol. 6, no. 1, Article ID 015318, 2016.

[17] . Seong-Dong Kim, S. Narasimha, and K. Rim, "An integrated methodology for accurate extraction of S/D series resistance components in nanoscale MOSFETs," in Proceedings of the IEEE InternationalElectron Devices Meeting, 2005. IEDM Technical Digest., pp. 149-152, Tempe, Arizon, USA.

[18] S.-D. Kim, "Optimum location of silicide/Si interface in ultrathin body SOI MOSFETs with recessed and elevated silicide source/drain contact structure," Solid-State Electronics, vol. 53, no. 10, pp. 1112-1115, 2009.

[19] C. Ortolland, E. Rosseel, N. Horiguchi et al., "Silicide yield improvement with $\mathrm{NiPtSi}$ formation by laser anneal for advanced low power platform CMOS technology," in Proceedings of the 2009 IEEE International Electron Devices Meeting (IEDM), pp. 1-4, Baltimore, MD, USA, December 2009.

[20] T. Matsukawa, Y. Liu, K. Endo et al., "Variability origins of parasitic resistance in finFETs with silicided source/drain," IEEE Electron Device Letters, vol. 33, no. 4, pp. 474-476, 2012.

[21] C.-W. Sohn, C. Y. Kang, M.-D. Ko et al., "Analytic model of S/D series resistance in trigate FinFETs with polygonal epitaxy," IEEE Transactions on Electron Devices, vol. 60, no. 4, pp. 13021309, 2013.

[22] R.-H. Baek, C.-K. Baek, S.-W. Jung et al., "Characteristics of the series resistance extracted from Si Nanowire FETs Using the Yfunction technique," IEEE Transactions on Nanotechnology, vol. 9, no. 2, pp. 212-217, 2010.

[23] Y. Taur and T. H. Ning, MOSFET Devices, in Fundamentals of modern VLSI devices, , Singapore, Cambridge University Press, Singapore, 2nd edition, 2010.

[24] T. Matsukawa, Y. Liu, S. Ouchi et al., "Comprehensive analysis of Ion variations in metal gate FinFETs for $20 \mathrm{~nm}$ and beyond," in Proceedings of the IEEE International Electron Devices Meeting (IEDM), pp. 517-520, 2011.

[25] R. A. Vega and T.-J. K. Liu, "A comparative study of dopantsegregated Schottky and raised source/ drain double-gate MOSFETs," IEEE Transactions on Electron Devices, vol. 55, no. 10, pp. 2665-2677, 2008.
[26] S. F. Feste, M. Zhang, J. Knoch, and S. Mantl, "Impact of variability on the performance of SOI Schottky barrier MOSFETs," Solid-State Electronics, vol. 53, no. 4, pp. 418-423, 2009.

[27] J. Yoon, E. Jeong, S. Lee et al., "Extraction of Source/Drain Series Resistance Components Optimized for Double-gate FinFETs," Japanese Journal of Applied Physics, vol. 54, no. 45, pp. 04DC061-04DC06-4, 2015.

[28] S. Xiong, T.-J. King, and J. Bokor, "A comparison study of symmetric ultrathin-body double-gate devices with metal source/drain and doped source/drain," IEEE Transactions on Electron Devices, vol. 52, no. 8, pp. 1859-1867, 2005.

[29] J.-S. Yoon, K. Kim, T. Rim, and C.-K. Baek, "Performance and variations induced by single interface trap of nanowire FETs at 7-nm node," IEEE Transactions on Electron Devices, vol. 64, no. 2, pp. 339-345, 2017.

[30] J.-M. Peransin, P. Vignaud, D. Rigaud, and L. K. J. Vandamme, "1/f Noise in MODFET's at Low Drain Bias," IEEE Transactions on Electron Devices, vol. 37, no. 10, pp. 2250-2253, 1990.

[31] S.-J. Choi, J.-W. Han, S. Kim, D.-I. Moon, M. Jang, and Y.-K. Choi, "Dopant-segregated schottky source/drain FinFET with a NiSi FUSI gate and reduced leakage current," IEEE Transactions on Electron Devices, vol. 57, no. 11, pp. 2902-2906, 2010.

[32] M. Christensen, V. Eyert, C. Freeman et al., "Formation of nickel-platinum silicides on a silicon substrate: Structure, phase stability, and diffusion from ab initio computations," Journal of Applied Physics, vol. 114, no. 3, Article ID 033533, 2013.

[33] T. Yamaguchi, K. Kashihara, T. Okudaira et al., "Suppression of Anomalous Gate Edge Leakage Current by Control of $\mathrm{Ni}$ Silicidation Region using Si Ion Implantation Technique," in Proceedings of the 2006 International Electron Devices Meeting, pp. 1-4, San Francisco, Calif, USA, December 2006. 

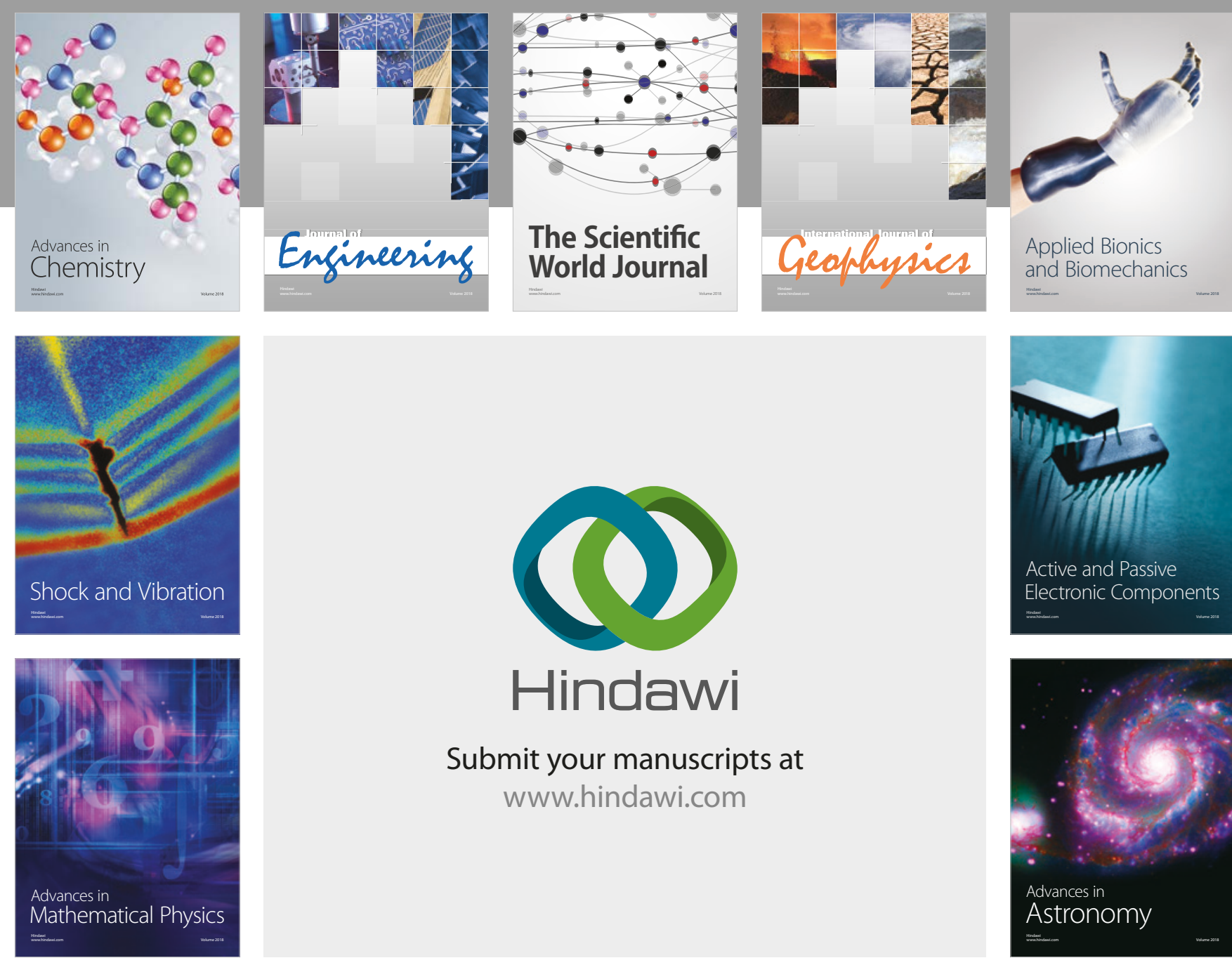

Submit your manuscripts at

www.hindawi.com

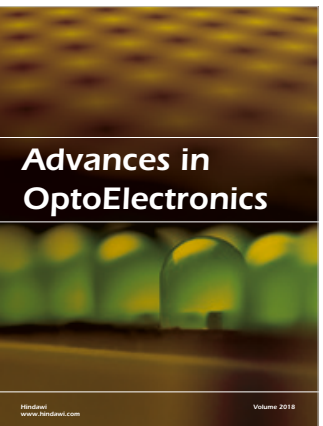

\section{Rotcting Machinery}


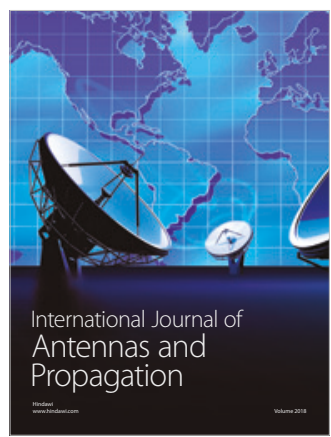

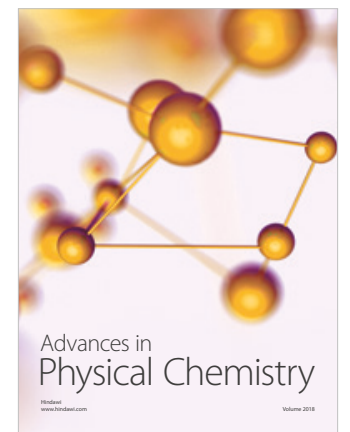

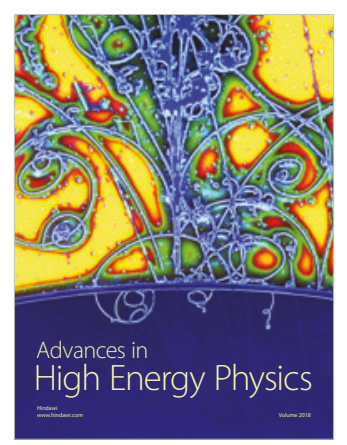

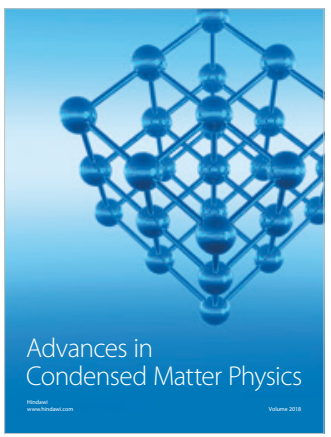

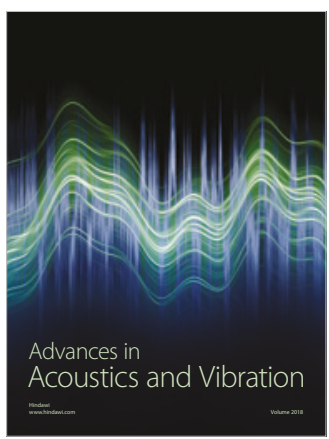

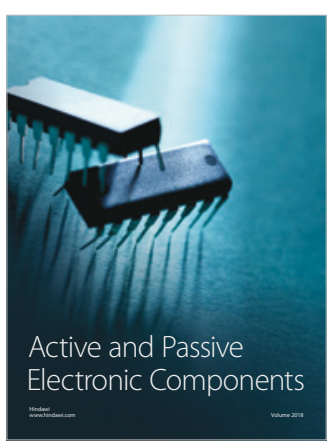
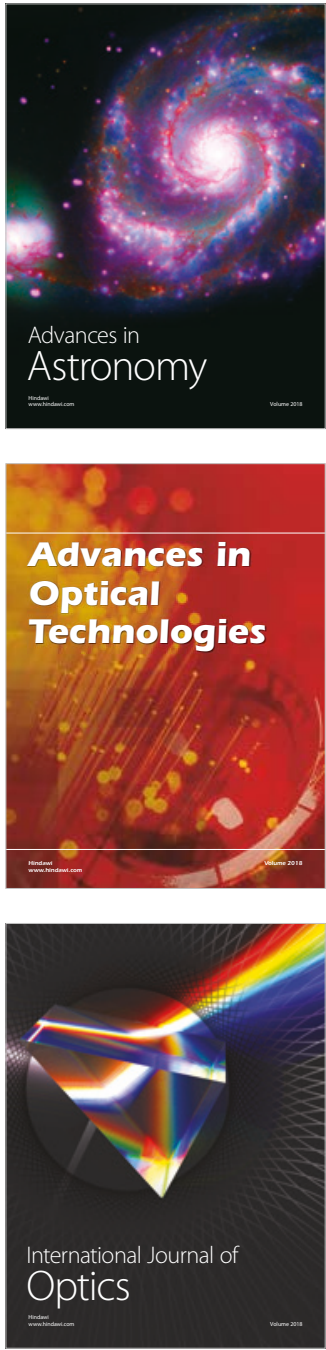